\title{
Efficacy of intravenous immunoglobulins in a patient with systemic lupus erythematosus presenting with Stevens-Johnson syndrome
}

\author{
Irma L Vázquez-Sanabria, ${ }^{1}$ Rogelio Mercado-Seda, ${ }^{2}$ Noemí Varela-Rosario, ${ }^{1}$ \\ Luis M Vilá ${ }^{1}$
}

\begin{abstract}
'Division of Rheumatology, Department of Medicine, University of Puerto Rico Medical Sciences Campus, San Juan, Puerto Rico 2Department of Dermatology, University of Puerto Rico Medical Sciences Campus, San Juan, Puerto Rico
\end{abstract}

\section{Correspondence to}

Dr Luis M Vilá,

luis.vila2@upr.edu

Accepted 11 July 2015
To cite: VázquezSanabria IL, MercadoSeda R, Varela-Rosario N, et al. BMJ Case Rep Published online: [please include Day Month Year] doi:10.1136/bcr-2015211157

\section{DESCRIPTION}

A 38-year-old woman with systemic lupus erythematosus (SLE) manifested by tiredness, polyarthritis, lymphopaenia, elevated antidouble-stranded DNA antibodies, and hypocomplementaemia was initiated on azathioprine and hydroxychloroquine. After 2 weeks of treatment, she developed extensive erythematous raised skin patches, facial oedema, and desquamation of nasal and oral mucosa. Both drugs were discontinued and she improved within 4-7 days. Since hydroxychloroquine is associated with more hypersensitivity reactions than azathioprine, the latter was reintroduced, but 2 days later, the patient developed severe recurrent skin lesions (figure 1A-C). Skin biopsy showed band-like lymphocytic infiltrate with focal vacuolar interface

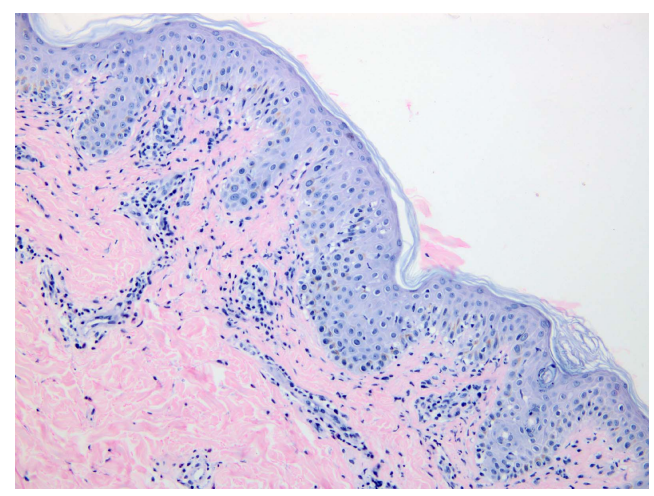

Figure 2 Skin biopsy showing band-like lymphocytic infiltrate with focal vacuolar interface changes consistent with early Stevens-Johnson syndrome.
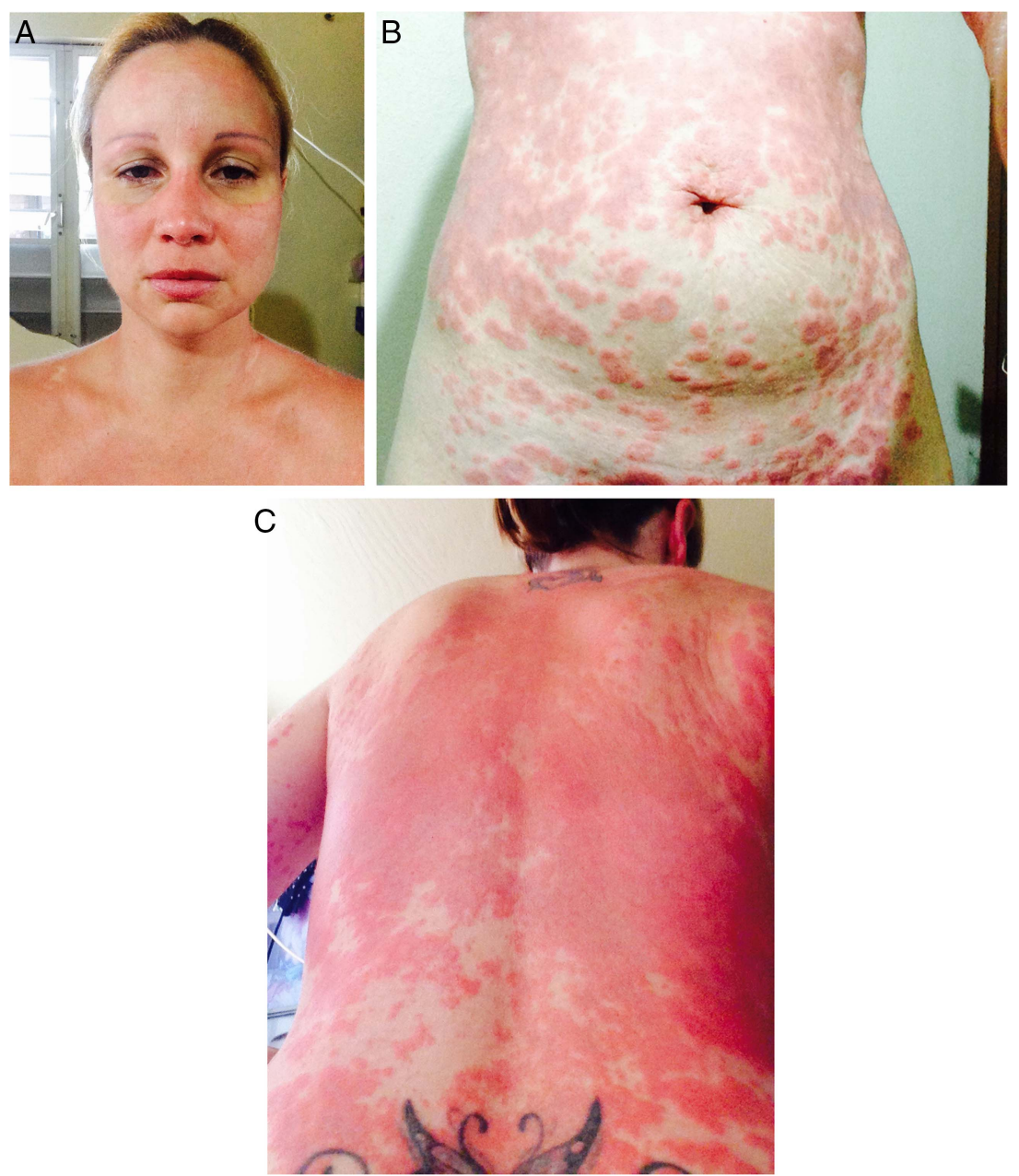

Figure 1 Skin lesions on the $(A)$ face, $(B)$ abdomen and $(C)$ back before intravenous immunoglobulin therapy. 

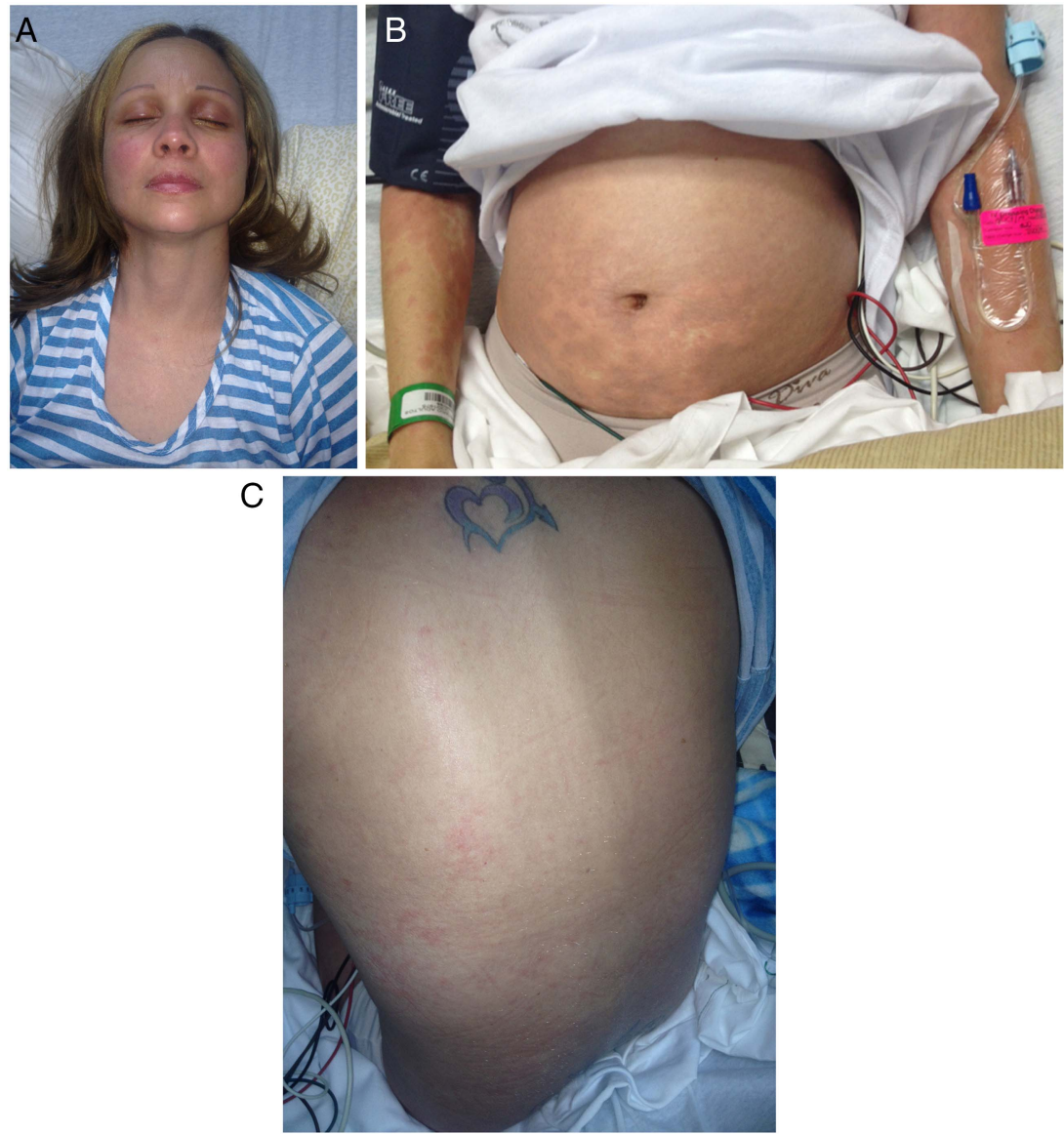

Figure 3 Skin lesions on the (A) face, (B) abdomen and (C) back $48 \mathrm{~h}$ after initiating intravenous immunoglobulin therapy.

changes consistent with early Stevens-Johnson syndrome (figure 2). She had no symptoms or signs of respiratory, urinary or soft tissue infection. Urine and blood cultures were negative. Chest X-rays were normal. She did not required antibiotics during the hospitalisation. She was treated with high-dose intravenous immunoglobulins (IVIGs) over a 5 -day period ( $30 \mathrm{~g} /$ day). After 2 days of initiating therapy, she improved as evidenced by resolution of facial oedema, and decreased erythema and desquamation (figure 3A-C). Hydroxychloroquine was restarted 5 months later without adverse events. The patient did not present recurrent lesions after 6-month follow-up.

\section{Learning points}

- Patients with systemic lupus erythematosus are at increased risk of developing Stevens-Johnson syndrome.

- We described a 38-year-old woman who developed Stevens-Johnson syndrome secondary to azathioprine, and who had a rapid recovery with intravenous immunoglobulin treatment.

- This case together with other reports suggests that the use of intravenous immunoglobulins for Stevens-Johnson syndrome may be effective in accelerating the recovery period and stopping the progression of skin disease.
Our patient developed Stevens-Johnson syndrome most likely secondary to use of azathioprine. She had a remarkable clinical response to IVIG. Patients with SLE have an increased risk for Stevens-Johnson syndrome either because of the SLE itself or due to the use of immunosuppressive drugs such as azathioprine. ${ }^{1}$ Since cutaneous adverse events to azathioprine are rare, they are usually recognised on resumption of therapy. ${ }^{2}$ These reactions are dose dependent and occur within the first 4 weeks of exposure. There is no consensus on whether IVIG is better than conservative therapy for Stevens-Johnson syndrome, but some reports have shown its efficacy. ${ }^{3}$ In summary, we present an additional case in which high-dose IVIG was successful in accelerating the recovery period and stopping further disease progression of Stevens-Johnson syndrome.

Competing interests None declared.

Patient consent Obtained.

Provenance and peer review Not commissioned; externally peer reviewed.

\section{REFERENCES}

1 Ziemer S, Kardaun SH, Liss Y, et al. Stevens-Johnson syndrome and toxic epidermal necrolysis in patients with lupus erythematosus: a descriptive study of 17 cases from a national registry and review of the literature. Br J Dermatol 2012;166:575-600.

2 Bidinger JJ, Sky K, Battafarano DF, et al. The cutaneous and systemic manifestations of azathioprine hypersensitivity syndrome. J Am Acad Dermatol 2011;65:184-91.

3 Stella M, Clemente A, Bollero D, et al. Toxic epidermal necrolysis (TEN) and Stevens-Johnson syndrome (SJS): experience with high-dose intravenous immunoglobulins and topical conservative approach. A retrospective analysis. Burns 2007;33:452-9. 
Copyright 2015 BMJ Publishing Group. All rights reserved. For permission to reuse any of this content visit http://group.bmj.com/group/rights-licensing/permissions.

BMJ Case Report Fellows may re-use this article for personal use and teaching without any further permission.

Become a Fellow of BMJ Case Reports today and you can:

- Submit as many cases as you like

- Enjoy fast sympathetic peer review and rapid publication of accepted articles

- Access all the published articles

- Re-use any of the published material for personal use and teaching without further permission

For information on Institutional Fellowships contact consortiasales@bmjgroup.com

Visit casereports.bmj.com for more articles like this and to become a Fellow 